\title{
The Theoretical Aspects of the Development of the Regional Scientific and Technical Products Market
}

\author{
Vladislav V. Ivchenko \\ Vladimir V. Belskii* \\ Immanuel Kant Baltic Federal University, Russian Federation \\ *Corresponding Email: vbelskii@kantiana.ru
}

\section{Doi:10.5901/mjss.2015.v6n6s7p116}

\begin{abstract}
The paper represents the authors' views on the theoretical aspects of the development of the regional scientific and technical products market. The aim of the work is to interpret the process of development (management) of such a market. The paper deals with the issues connected with structuring and determining the behaviour of change of the scientific and technical products market. Also, an information and logical model was proposed as well as a generic aggregatory network model of the programme of establishment of the market in question for small to medium-sized enterprises on the principles of state support. The proposed approach provides an alternative point of view of the processes of commercialisation of the results of scientific and technological activities. From the research and practical perspective, the described methodology is seen as a basis for the further in-depth elaboration of the issues of development of the regional scientific and technical products market.
\end{abstract}

Keywords: S\&T, regional product market, RSTPM structure, RSTPM development, generic network model

\section{Introduction}

The transition of Russia's economy from the centralized planning to market relations was extremely difficult, involving even some dramatic stages as was the case in 1994 and 1998. It was, first and foremost, connected with the changes of the patterns of ownership, rushed privatization and arduous establishment of market mechanisms. The development of market relations and the formation of markets for their output were erratical for various segments of spheres of the country's economic activities. This had a negative impact on the crisis recovery and the pace of development of the country's economy.

In this respect, it seems appropriate to consider such an important for the fortunes of Russia's economy issue as the development of the innovative scientific and technical products (STP) market. The notion 'scientific and technical products' stands for: technical documentation, pilot specimens, pilot batches, preproduction prototypes, models, patterns, research reports, as well as separate kinds of works executed under order (tests, managed maintenance, technical operations etc.) (R 50-605-80-93, 1993). STP market is a base for the establishment of platforms of new technologies including innovations, ensuring the output of competitive products of both separate economic sectors and the economy of the country as a whole.

It should be noted that in Russia as early as in the Czarist-era a sustainable system of state funding of scientific and technical activities was established that continued in the Soviet period. And it must be said that in many respects it worked, securing the country's faster advancement in different areas of science and technology and, first of all, in the defense sphere. However, in 1987 first steps were made to establish scientific and technical cooperatives. In 1992-1994, cautious, though occasionally not quite effective, privatization of science started which, first and foremost, affected design organizations and research and manufacturing associations (RMA). The process was preceded by extremely poor preparation and took place under the conditions of muddled privatization of manufacturing industry and a severe economic crisis. The state failed to traditionally finance science having drastically reduced the funds, and the manufacturing industry having lost its own current assets and amortization savings as a consequence of inflation, was also unable to finance within the necessary limits even applied research. The development of the domestic market of STP and innovations fell dramatically behind the establishment of industrial products markets for many years. In fact, it was only by 2010-2011 that the development of STP markets started to take shape. Unfortunately, as the practice of the past few years show, those markets were chiefly orientated to the imported STP that hampered the development of Russian science and technology. One of the urgent issues of today's economy of Russia is the task of conceptualization of the 
ways of development of regional STP markets orientated, first of all, to enhancing the competitive abilities of small to medium-sized enterprises (SME).

\section{Market of Scientific and Technical Products}

The notion of 'development of STP markets' implies, first and foremost, managing the process of development since the matter actually concerns a quasi-market ${ }^{1}$ necessary to ensure a fast introduction into the economic turnover of the outcomes of scientific and technical activities. From the applicative point of view, it is an extremely challenging task involving the consideration of a great deal of impacts of both external and internal factors (Bilchak \& Nosachevskaya, 2010; Mikhaylova \& Mikhaylov, 2015). The task is also complicated by the fact that the issue under consideration has not been elaborated sufficiently in the Russian research literature, and foreign literature is lacking an immediate equivalent to the notion "scientific and technical products market", while the closest in meaning are the notions of "market for ideas", "market for (new) technologies" and "market for intellectual property rights" which, according to experts, do not differ considerably from the markets conventional of the economic science (Boldrin \& Levine, 2005; Gans et al., 2008; Mikhaylova \& Mikhaylov, 2016).

Drawing on studying the experience of development of STP markets in foreign countries, in particular in France, Norway, Finland - based on the authors' experience and additional materials (Cooke, 1996; Avdulov \& Kulkin, 2005; Rubvalter \& Rudenskii, 2007; Shaimieva \& Gumerova, 2010; Gadzhiev et al., 2013) - two large stages of the development process can be identified.

A first stage is connected with a strong support of the initial stage of development of a regional STP market ${ }^{2}$ on the part of public and municipal authorities by means of the following: the elaboration of legal bases ${ }^{3}$ of development and functioning of such markets, the establishment of favourable economic conditions in the form of tax benefits, credit granting, promotion of network interaction between the elements of innovation infrastructure etc., and also by a substantial scheme of government orders.

A second stage following a first is characterized by the maturity of those markets and their transition to the independent sustainable functioning, i.e. to the mode of economic homeostasis. The research into these processes as applied to the conditions of Russia has been scarce so far. This, first of all, regards theoretical developments (Bilchak \& Nosachevskaya, 2010; Ivchenko \& Belskii, 2015).

In theoretical terms, the process of development and further sustainable self-sufficient functioning of regional STP markets should be considered from the stance of systemic analysis. But before looking into the model of development of the STP market, a developer is challenged two tasks: how to structure STP markets on the whole in Russia, and what the regularities of behaviour pattern of the change of development of regional STP markets are. These are extremely complex tasks that require conducting independent studies - the STP market is characterized by a great diversity of spheres of industrial application of its output, and this diversity is constantly expanding (John et al., 1999). Nevertheless, in terms of discussion they can be considered within the following areas.

From the perspective of a hierarchical approach, the entire structure of STP markets of Russia can be conditionally represented in the form of an inverted pyramid. It has a range of levels. For the convenience of the analysis, it seems reasonable to distinguish three levels: the nationwide Russian intersectorial STP markets, regional intersectorial STP markets and regional STP markets of small to medium-sized enterprises (SME). Their borders are blurred and they are interconnected by a complex system of horizontal and vertical links (Figure 1).

Of special interest are regional STP markets of SME, where STP acts as a catalyser of modernization of industrial production of SME. SME are most numerous, and in terms of relative share in the macroeconomic estimates of the

\footnotetext{
${ }^{1}$ In the course of formation of a new market, one should bear in mind that a market must fulfill at least three functions: (1) integrate quite a large number of customers and contractors, (2) ensure safety as regards information confidentiality preservation, and (3) facilitate (not counter) the pace of transactions (Roth, 2007).

${ }^{2}$ The regional scientific and technical products market implies the regional scheme of regular, mutually beneficial, voluntary and competitive exchange of scientific and technical products, where the demand and supply depend, apart from prices, on the character of the scientific-technological progress in the region and in the world, on the institutional forms of supporting innovation activities in the region and in municipalities, on the presence and the level of training of specialized labor resources, on the character of power hierarchies and cultural constructs in the region. The definition of the term is based on the definition of the notion "market" from the stance of economic and sociological approach (Radaev, 2007).

${ }^{3}$ Notably, an important aspect is the improvement of the mechanisms of affixing the rights of ownership of the results of scientific and technical activities, since the transactions on the market of scientific and technical products imply quite detailed contract-based relationships (Arora et al., 2001).
} 
regions, they rank high (in GRP, by the number of the employed, by the turnover etc.). As per sectoral distribution on average, they comprise the following: $70 \%$ of commerce and service enterprises; $30 \%$ enterprises operating in the sphere of transport, construction, repairs, industrial products and agro-sector. Under the conditions of competitive environment, they are quite vulnerable and effectively need new technologies and developments of STP in order to survive. That is why for them the development of the STP market and the supporting infrastructure ${ }^{4}$ serves as a most important means of stabilization and development.

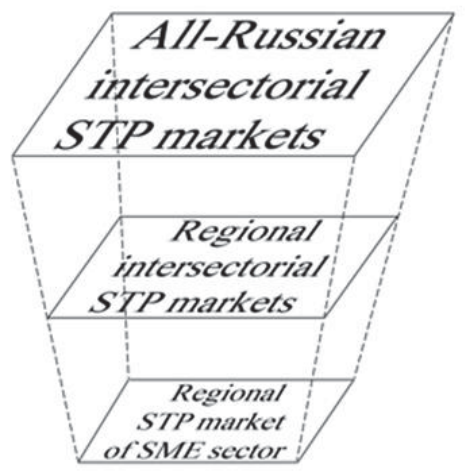

Figure 1. Conventional-logical structure chart of STP markets in Russia

The theory of innovative (including also STP) regional development has a notion of a "technological wave" (Ivchenko, 2006). Its judgmental estimate can be conducted by three quite sound criteria of technology maturity: new developing technologies; firmly established modern technologies; and obsolescent technologies.

They comply with three stages of the life cycle of scientific and innovation activities that ensure a competitive development of SMEs of the region. It is apparent that they should be aligned with certain stages of the STP market of the region for these enterprises. In theoretical terms, combining these technologies with their market conditions we can elicit a representation of a dynamic pattern of regional STP markets based on the principles of innovative wave of the region (Figure 2).

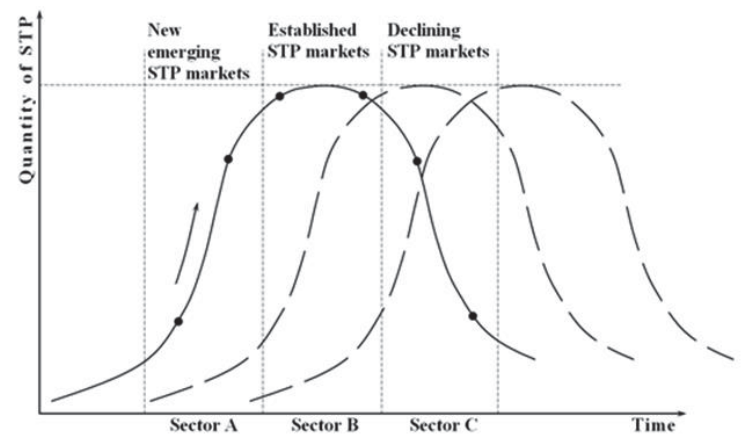

Figure 2. Theoretical representation of dynamic pattern of the RSTPM (based on the principles of innovative technological wave)

\footnotetext{
${ }^{4}$ The infrastructure of the RSTPM is included in the innovation infrastructure of the region and is based on the institutions involved in organizing and supporting the exchange of results of scientific and technical activities. The RSTPM infrastructure can include centres for technology transfer, centres for sub-contraction, centres and foundations for supporting small to medium-sized enterprise, venture capital funds, centres for scientific and technical information, research and education centres, consulting organizations, exhibition and fair centres etc.
} 
The curve in the Figure clearly shows the evolution dynamics of the regional STP market comprising of three stages:

- new emerging STP markets;

- established STP markets; and

- declining STP markets.

These stages are fast-paced and alternate in the course of time (Medynskii \& Skamai, 2002; Ivchenko, 2006; Ivchenko, 2010) being within the system of development and functioning of the regional STP market.

\section{Regional Scientific and Technical Products Market (RSTPM)}

As experience proves a first stage of managing (development) of the regional scientific and technical products market (RSTPM) needs strong state (including municipal) support in order to go fast. The conceptualization of managing the development of RSTPM results in the understanding of the necessity of describing it as a certain information-logical model built on the principles of a systemic approach. The model features clear systemic elements: the aims of RSTPM establishment and development, the information and material entry and outcome, the external and internal limitations, the criteria for evaluation of the set aims, the internal process content, a developed feedback mechanism between the outcome and the entry and between the internal elements. The model is open and it is actively interacting with the external environment (Figure 3). Four internal nodes must be, first of all, identified in it (Ivchenko, 2006; Ivchenko, 2010).

Node 1. The development of a targeted regional programme of RSTPM development on the principles of state support.

Node 2. The elaboration of events aimed at the establishment of RSTPM infrastructure.

Node 3. The establishment of regulators and securing launching implementation of the programme and the RSTPM functioning.

Node 4. The estimation and ensuring competitiveness of development of the region's economy on the basis of the RSTPM establishment.

It should be noted that those nodes and other parts of the information-logical model of the system of RSTPM development are constantly interacting.

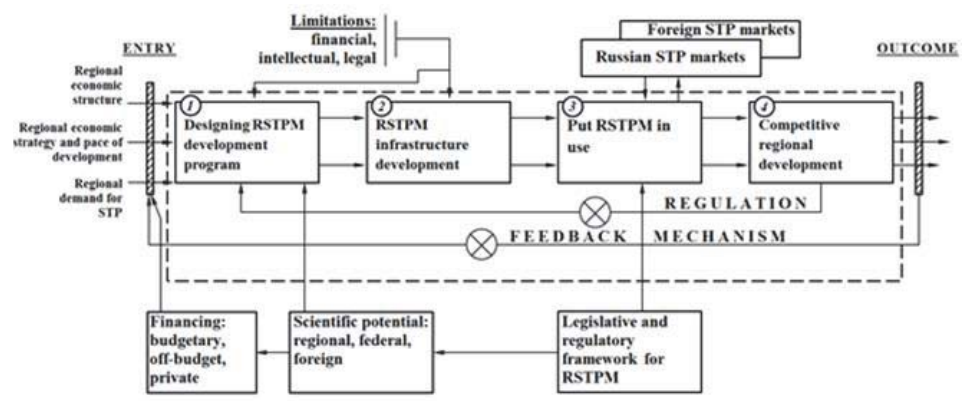

Figure 3. Information-logical model of the system of RSTPM development (launching stage)

The theoretical representation of the RSTPM development creates an opportunity to design a methodology and to elaborate, first and foremost, a programme of the RSTPM development for a SME region. It is worth mentioning that the scientific and technical products acquire a commodity form only on the RSTPM. The market is supposed to interact and function along with the other region's markets: that of labour, capital, material and financial resources etc. A developed market of STP exhibits a property for self-regulation and self-improvement which promotes the enlargement of the market and considerably enhances its influence on the growth of the economy and competitive power of the region.

The transfer of the information-logical model of the RSTPM development to the research and practice area requires, first of all, partitioning of its first node - the design of the programme of the process on the principles of state support. This will enable us to logically systematize all the events for the further elaboration of a topology and a working organizational model of managing the RSTPM development.

The issue was structured through the example of RSTPM for a SME region based on both Russian and foreign experience, as well as methods of hierarchy and PATTERN (Figure 4). 
The analysis identified three sub-aims (areas): analytical section; planning section; and organizational section.

On the basis of the information-logical analysis, the main programme events were determined for each area which will enable us to design a network model of managing the RSTPM development for a SME sector.

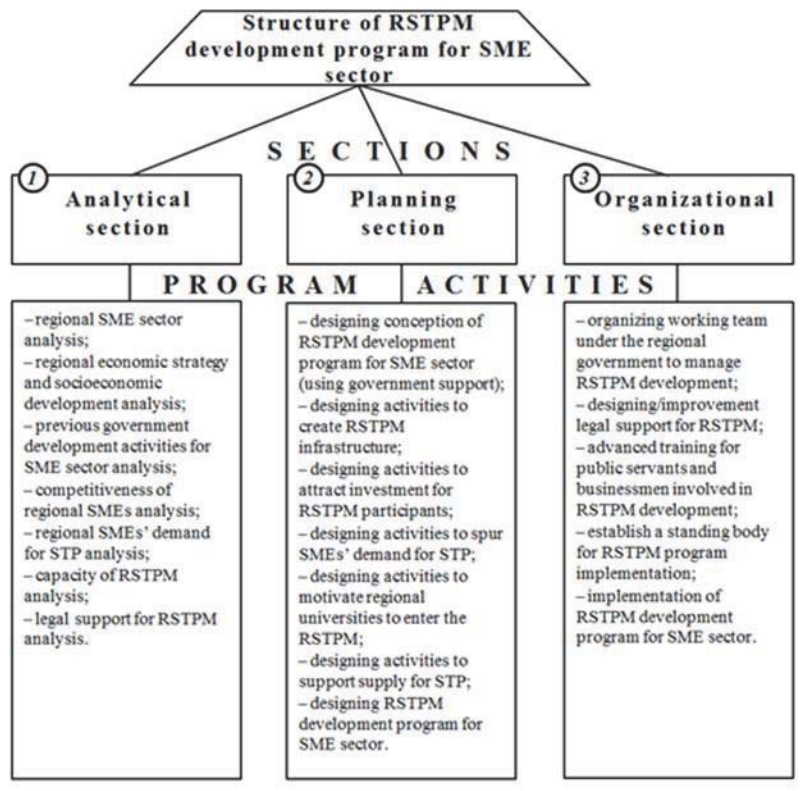

Figure 4. Tree diagram of the main events of the programme of RSTPM development on the principles of state support (launching stage)

By means of information-logical analysis, logical links (actual or fictitious) are established between these events and the technology of the entire process of managing the RSTPM development is specified. This enables us to build an exemplary topology (i.e. a certain framework) of a network model of the RSTPM development. In accordance with the simulation methodology (Ivchenko, 2008) based on the topology which is used as a concept for designing a specific model, a preliminary model and then a working network model of the programmes of the RSTPM development are elaborated in a successive order. For small- and medium-scale models, the stage of preliminary design can be omitted. The models themselves can be plotted with the help of different techniques - PERT or OSMO. Effectively, a working network model serves as the main framework agency for the organization of managing the RSTPM development. Figure 5 shows a first developed exemplary scaled-up network model of the programme of the RSTPM development through the example of a SME sector on the principles of state support. Effectively, the working model after its disaggregation is increased in the ratio of 1:8(10), i.e. in this case it will comprise $160 \div 200$ events.

The analysis of foreign and domestic experience of using network models in managing different socio-economic and technological processes testifies to their high efficiency. They are instrumental in reducing the timeframe of those processes implementation up to $25 \%$ and lowering the costs to $10 \%$. It is quite pronounced that they will also be able to play a big role in managing such a complex socially important process as the RSTPM development.

\section{Conclusions}

The theoretical conceptualization of the ways of development of regional scientific and technical products markets orientated primarily to enhancing the competitive abilities of small to medium-sized enterprises, is an urgent issue for the present-day Russian economy. The experience analyzed gives evidence that the process of development (management) of such markets includes, as a rule, two chronological stages - the first stage is connected with strong state and municipal support, and the second is characterized by an independent coherent functioning of the markets in question.

It is reasonable to consider the said market from the point of view of a system analysis - the market is preliminary 
patterned with the use of hierarchical approach and the principles of innovative technological wave.

The process of managing the development of the market in question can be described by an open informationlogical model. Subsequently, the model can be transferred to the research and practice sphere due to disaggregation of its sections and elements. In particular, in this paper we partitioned the section of elaboration of the programme of supporting the regional scientific and technical products market on the principles of state aid. This resulted in the development of a consolidated network model which is capable of serving as the main organizing agency of managing the market under consideration.

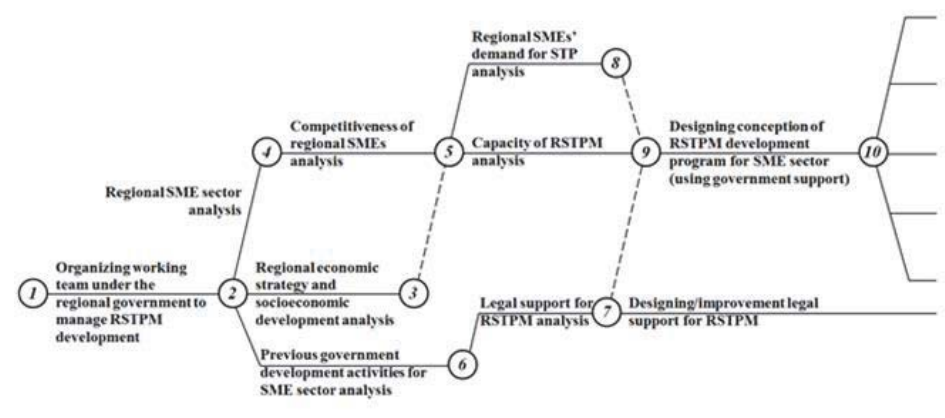

Figure 5. Exemplary topology of consolidated network model of the programme of RSTPM development for SME sector on the principles of state aid

Note: WG - working group; RSTPM - regional scientific and technical products market; SED - socio-economic development of the region; SME - small to medium-sized enterprises

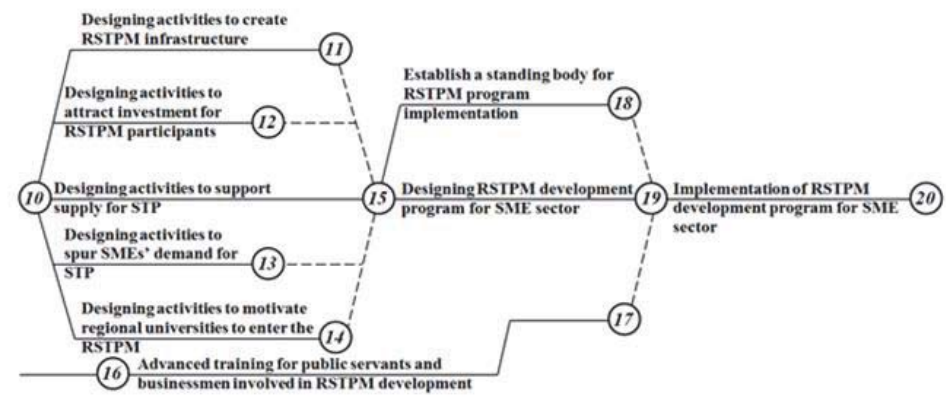

Figure 5. (continuation)

\section{References}

Arora, A., \& Fosfuri, A., \& Gambardella, A. (2001). Markets for Technology: The Economics of Innovation and Corporate Strategy. MIT Press, Cambridge MA.

Avdulov, A.N., \& Kulkin, A.M. (2005). Scientific and technological parks, technopolises and regions of science. M.: The Institute of Scientific Information for Social Sciences RAS.

Bilchak, V.S., \& Nosachevskaya, E.A. (2010). The development of research activities in the region: Monograph. Kaliningrad: IKSUR Publishing House.

Boldrin, M., \& Levine, D. (2005). The economics of ideas and intellectual property. Proceedings of the National Academy of Sciences. 102(4). P. 1252-1256.

Cooke, P. (1996). The New Wave of Regional Innovation Networks: Analysis, Characteristics and Strategy. Small Business Economics. Vol. 8, No. 2, Special Issue on Geography and Regional Economic Development: The Role of Technology-Based Small and Medium Sized Firms (Apr., 1996). P. 159-171.

Gadzhiev, M.M., Yakovleva, E.A., \& Buchaev, Ya. G. (2013) Techniques of financing science in the USA and Norway. Economic 
systems management: electronic scientific journal. No10(58).

Gans, J., Hsu, D., \& Stern, S. (2008). The Impact of Uncertain Intellectual Property Rights on the Market for Ideas: Evidence from Patent Grant Delays. Management Science. 54(5). P. 982-997.

Ivchenko, V.V. (2006). An outline of innovative economy of Russia's maritime regions: Monograph. Kaliningrad: IKSUR Publishing House.

Ivchenko, V.V. (2008). Network programming of development of Russia's maritime regions: Monograph. Kaliningrad: IKSUR Publishing House.

Ivchenko, V.V. (2010). The development of innovative infrastructure of Russia's maritime region - simulation of development management: Monograph. IKSUR Publishing House.

Ivchenko,V.V., \& Belskii, V.V. (2015). Scientific and technical products market of an exclave region: issues of development. Collection of research papers "Socio-economic position of the Kaliningrad Oblast": BSARF Publishing House.

John G., Weiss A., \& Dutta, S. (1999). Marketing in Technology-Intensive Markets: Toward a Conceptual Framework. Journal of Marketing. 63, 78-91.

Medynskii, V.G., \& Skamai, L.G. (2002). Innovative entrepreneurism: Textbook. M.: UNITY.

Mikhaylova, A.A., \& Mikhaylov, A.S. (2015). Antecedents and Barriers to the Formation of Regional Innovation System: Case Study of the Kaliningrad Region. Modern Applied Science, 9 (2), 178-187.

Mikhaylova, A.A., \& Mikhaylov, A.S. (2016). Re-distribution of knowledge for innovation around Russia. International Journal of Technological Learning, Innovation and Development. Forthcoming. Available at: http://www.inderscience.com/info/ingeneral/ forthcoming.php?jcode=ijtlid

$R$ 50-605-80-93 Recommendations. A system of production elaboration and engineering. Terms and definitions. Approved by the order of the National Research Institute of Standard of July 9, 1993, No18.

Radaev, V.V. (2007). What is a market: economic and sociological approach. Economic sociology. V. 8. No1. pp. 9—26.

Roth, A.E. (2007). The Art of Designing Markets. Harvard Business Review. October.

Rubvalter, D.A., \& Rudenskii, O.V. (2007). Finland: science, technologies, innovations. Research and information report of CRSS. No4. Pp. 3-53.

Shaimieva, E.Sh., \& Gumerova, G.I. (2010). Research into the issues of innovative and technological development of a region on the basis of principles of open innovations. Innovations. 7 (141), 71-75. 